EDITORIAL

\title{
Is undergraduate ophthalmology teaching in the United Kingdom still fit for purpose?
}

(C) The Author(s), under exclusive licence to The Royal College of Ophthalmologists 2021

Eye (2022) 36:343-345; https://doi.org/10.1038/s41433-021-01756-y

\section{INTRODUCTION}

There is a growing crisis in ophthalmology education. An increasing number of junior doctors and general practitioners are losing confidence in their ophthalmic knowledge; this includes a declining use of the fundoscope [1], associated loss in confidence with recognising sight-threatening pathologies [2], and a consequential rise in inappropriate referrals to tertiary eye units [3]. Furthermore, modern medical curriculums in the UK are becoming increasingly 'crowded', resulting in many academic institutes prioritising subjects that align with the broader learning objectives of the General Medical Council (GMC). These include the colonisation of novel undergraduate topics and less time for the basic sciences [4]. Over the last two decades, ophthalmology has witnessed a decline in teaching from 2-week clinical rotations [5] to altogether noncompulsory in a modern curriculum [6]. Greater attention is required to the state of undergraduate ophthalmology training in the United Kingdom (UK).

These curriculum changes have meant that there is limited teaching for ophthalmology at an undergraduate level. Presently, in the UK, a clinical rotation in ophthalmology is non-compulsory in certain medical schools and the vast majority of teaching revolves around traditional methods, such as didactic lectures, workshops and textbooks [6]. These methods are not conducive to efficient knowledge transfer [7], or supporting the current digital era of learning. As a result, over half $(52 \%)$ of senior medical students do not feel confident in their ophthalmic knowledge and three-quarters (75\%) feel their respective medical school's methodology of delivering ophthalmology education is inadequate [6]. Adjunctive educational methods need to be adopted in ophthalmology to combat the constraints of modern medical curriculums, improve student confidence in ophthalmology, and to future-proof undergraduate ophthalmology education.

\section{BLENDED LEARNING}

Blended learning is the provision of supplementary resources that support education in the traditional, virtual and self-directed learning environments [8]. This approach is especially applicable to ophthalmology since the specialty has lost time in the undergraduate curriculum, resulting in less room for passive learning through didactic lectures and clinical observership [6]. Blended learning provides a unique solution to support selfdirected, active learning techniques that foster an ethos of lifelong learning amongst undergraduate medical students [8]. Active learning can be facilitated using a 'flipped classroom' (FC) approach, which has been successfully integrated into a twoweek ophthalmology rotation in the United States by Kivell and colleagues [9]. Prior to clinical placement, medical students were allowed to undertake self-directed 90-minute porcine eye dissection following short lectures. This method allowed students to grasp clinically-relevant complex eye and orbital anatomy using an active learning style. Alternatives are available to dissection, should a more cost-effective method be required as a preclassroom activity $[10,11]$. The FC approach has grown popular in multiple ophthalmology units as a method to improve both knowledge gain and student satisfaction $[9,12,13]$.

A variety of pre-classroom resources are necessary for the FC approach to remain an attractive solution for individualised learning amongst students rotating through ophthalmology. Teaching resources can include three-dimensional ophthalmic models [10, 11], virtual ophthalmic software [14, 15], and multimedia modalities $[13,16]$. Following pre-classroom activities, the remaining time can be spent supporting higher cognitive domains: applying clinical knowledge to patient cases and troubleshooting more challenging concepts with senior ophthalmology faculty. Finally, medical education is changing to account for the exponential rise in technology, greater accessibility to the internet, and falling costs of digital devices [17]. As a result, there is a growing emphasis on using technology to assist blended

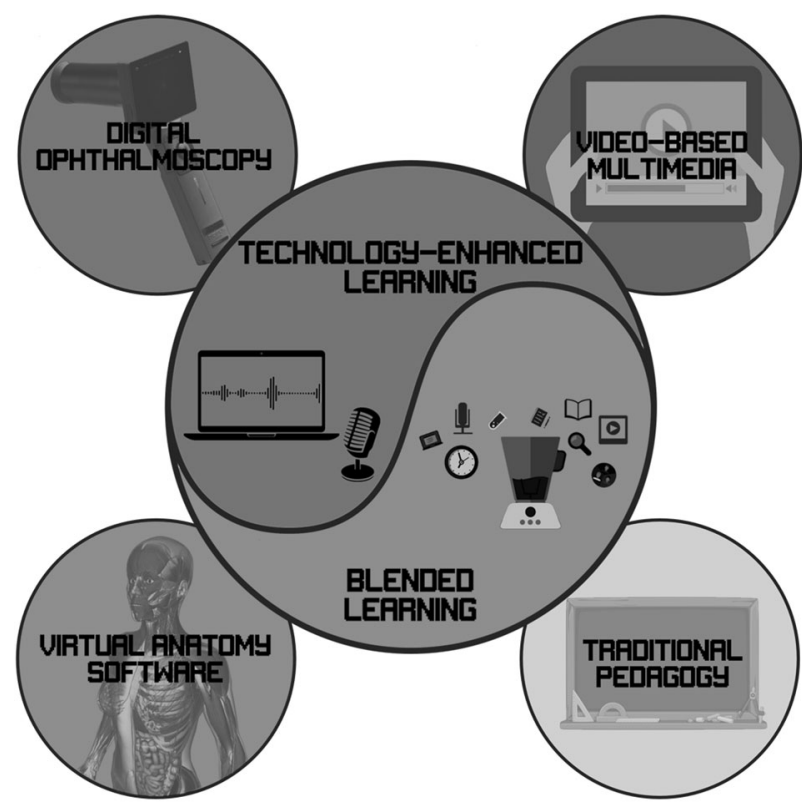

Fig. 1 A new model for undergraduate ophthalmology teaching. 'Technology-enhanced learning' (TEL) has multiple elements, including digital ophthalmoscopy, virtual anatomy software and videobased multimedia to be integrated as part of traditional teaching in a 'blended learning' approach. 
Table 1. Brief summary of technology-enhanced learning (TEL) resources available to teachers involved in undergraduate ophthalmology education that can be integrated into a traditional curriculum.

\begin{tabular}{|c|c|}
\hline Author (Date) & Brief description of study and TEL methodology \\
\hline Steedman (2012) [13] & $\begin{array}{l}\text { Randomised control trial exploring the use of video-based multimedia versus textbook resources on topics of acute vision } \\
\text { loss and cataracts. }\end{array}$ \\
\hline Succar (2013) [14] & Randomised control trial exploring the use of virtual ophthalmology clinics versus traditional ophthalmology placement. \\
\hline Schulz (2016) [21] & $\begin{array}{l}\text { Randomised control trial exploring the use of digital teaching ophthalmoscope compared to conventional } \\
\text { ophthalmoscope on clinical exam performance. }\end{array}$ \\
\hline Mamtora (2018) [19] & $\begin{array}{l}\text { Cross-sectional study examining smartphone-assisted ophthalmoscopy (D-EYE) compared to conventional } \\
\text { ophthalmoscope. }\end{array}$ \\
\hline Shikino (2019) [20] & $\begin{array}{l}\text { Randomised control trial exploring the use of smartphone-assisted ophthalmoscopy (iExaminer) compared to conventional } \\
\text { ophthalmoscope on diagnostic accuracy and timing till diagnosis of students. }\end{array}$ \\
\hline Lee (2019) [22] & $\begin{array}{l}\text { Proof-of-concept study describing the use of digital camera attachment for slit-lamp examination to produce live high- } \\
\text { quality images of an ophthalmic examination. }\end{array}$ \\
\hline
\end{tabular}

learning techniques as both students, pedagogues and academic institutes enter an era of 'digital learning' (Fig. 1) [14, 18-20].

\section{TECHNOLOGY-ENHANCED LEARNING}

Technology-enhanced learning (TEL) is an umbrella term for educational resources that employ digital devices, e-Learning material and virtual learning environments to enhance the student learning experience [18]. The benefits of employing TEL resources in undergraduate ophthalmology education are multifaceted, providing interactivity, accessibility and flexibility for learners during shorter ophthalmology placements. Most importantly it appeals to 'digital natives', the label given to current medical student belonging to generation $Y$ and $Z$. These student cohorts subconsciously seek to integrate TEL resources as part of their undergraduate ophthalmology learning. This includes the use of 3D virtual software to learn ocular anatomy [15], digital devices to support clinical skills [19-22], and virtual learning environments to support ophthalmology placements (Table 1) [14]. Our group at Sussex Eye Hospital (Brighton, UK) used BioDigital (NY, USA) to teach ocular anatomy to undergraduate students using a blended learning approach and $70 \%$ of students stated they would integrate the resource with future learning (unpublished).

In addition, video-based TEL has exponentially grown in the last two decades. In some cases, 'YouTube'-the largest online video repository-has been labelled as the first resort for learning new concepts in medicine or allied healthcare subjects [23]. The case is no different for ophthalmology education where there are numerous free, online and accessible educational videos produced by experienced pedagogues [24, 25]. Educational videos can be easily created by educationalists and guide students through purposeful narration to support self-directed learning, as well as reduce learning time with no compromise on knowledge retention [13].

\section{CONCLUSIONS}

Ophthalmology remains one of the most technologically up-todate specialties in healthcare, yet this is not reflected in our educational methods. Undergraduate ophthalmology education is in dire need of reform as junior doctors are losing confidence in assessing ophthalmic complaints and undergraduate students are dissatisfied with traditional teaching methods. Our advice to educators is to avoid the temptation to fall back on traditional teaching methods, but rather embrace TEL as part of a blended learning approach. TEL has been shown to reduce learning time, improve knowledge retention and enhance student engagement, especially amongst digital learners. The limited time left in a clinical rotation needs to be prioritised for applying and evaluating ophthalmic theory to patient cases, and not encountering elementary knowledge for the first time. We hope educationalists remain brave in exploring this new era of digital learning to ensure the longevity of ophthalmic knowledge in our future healthcare workforce and to make ophthalmology an enjoyable topic to learn for students.

\section{Y. Scantling-Birch (iD) ${ }^{1 凶}$, H. Naveed ${ }^{2,3}$, N. Tollemache ${ }^{4}$, P. Gounder ${ }^{5,6}$ and S. Rajak ${ }^{3,5}$}

${ }^{1}$ Department of Medicine, Royal Sussex County Hospital, University Hospitals Sussex NHS Foundation Trust, Brighton, UK. ${ }^{2}$ Ophthalmology Unit, Royal Surrey County Hospital, Royal Surrey NHS Foundation Trust,

Surrey, UK. ${ }^{3}$ Brighton and Sussex Medical School, Falmer Campus,

Brighton, UK. ${ }^{4}$ Department of Medicine, Manchester Royal Infirmary, Manchester University NHS Foundation Trust, Manchester, UK. ${ }^{5}$ Department of Oculoplastics, Sussex Eye Hospital, University Hospitals Sussex NHS Foundation Trust, Brighton, UK. ${ }^{6}$ Ophthalmology Unit, Royal Perth Hospital, The University of Western Australia, Perth, WA, Australia. ${ }^{凶}$ email: yarrow.scantling-birch@nhs.net

\section{REFERENCES}

1. Schulz C, Hodgkins P. Factors associated with confidence in fundoscopy. Clin Teach. 2014;11:431-5.

2. Yusuf $\mathrm{IH}$, Salmon JF, Patel CK. Direct ophthalmoscopy should be taught to undergraduate medical students-yes. Eye .2015;29:987-9.

3. Davey CJ, Green C, Elliott DB. Assessment of referrals to the hospital eye service by optometrists and GPs in Bradford and Airedale. Ophthalmic Physiol Opt. 2011;31:23-8.

4. Drake RL, McBride JM, Lachman N, Pawlina W. Medical education in the anatomical sciences: the winds of change continue to blow. Anat Sci Educ. 2009;2:253-9.

5. Shuttleworth GN, Marsh GW. How effective is undergraduate and postgraduate teaching in ophthalmology? Eye (Lond). 1997;11:744-50.

6. Tariq F, Loutfi M, Ghouri N, Watts M. Survey of current undergraduate ophthalmology teaching in the United Kingdom. Eye News. 2019. Available at: https://www.eyenews.uk.com/features/ophthalmology/post/survey-of-currentundergraduate-ophthalmology-teaching-in-the-united-kingdom. [Accessed October 10, 2020].

7. Freeman S, Eddy SL, McDonough M, Smith MK, Okoroafor $\mathrm{N}$, Jordt $\mathrm{H}$, et al. Active learning increases student performance in science, engineering, and mathematics. Proc Natl Acad Sci USA. 2014;111:8410-5.

8. Schwartzstein RM, Roberts DH. Saying goodbye to lectures in medical school paradigm shift or passing fad? N. Engl J Med. 2017;377:605-7.

9. Kivell TL, Doyle SK, Madden RH, Mitchell TL, Sims EL. An interactive method for teaching anatomy of the human eye for medical students in ophthalmology clinical rotations. Anat Sci Educ. 2009;2:173-8.

10. Adams JW, Paxton L, Dawes K, Burlak K, Quayle M, McMenamin PG. 3D printed reproductions of orbital dissections: a novel mode of visualising anatomy for trainees in ophthalmology or optometry. Br J Ophthalmol. 2015; 99:1162-7. 
11. Smith CF, Tollemache N, Covill D, Johnston M. Take away body parts! An investigation into the use of 3D-printed anatomical models in undergraduate anatomy education. Anat Sci Educ. 2018;11:44-53.

12. Xiong L, Ding XY, Fan $Y Z$, Xing $Y$, Zhang $X H$, Li T, et al. A novel three-dimensional electric ophthalmotrope for improving the teaching of ocular movements. Int J Ophthalmol. 2019;12:1893-7.

13. Steedman M, Abouammoh M, Sharma S. Multimedia learning tools for teaching undergraduate ophthalmology: results of a randomized clinical study. Can J Ophthalmol. 2012;47:66-71.

14. Succar T, Zebington G, Billson F, Byth K, Barrie S, McCluskey P, et al. The impact of the Virtual Ophthalmology Clinic on medical students' learning: a randomised controlled trial. Eye (Lond). 2013;27:1151-7.

15. Allen LK, Bhattacharyya S, Wilson TD. Development of an interactive anatomical three-dimensional eye model. Anat Sci Educ. 2015;8:275-82.

16. Hogg HDJ, Pereira M, Purdy J, Frearson RJR, Lau GB. A non-randomised trial of video and written educational adjuncts in undergraduate ophthalmology. BMC Med Educ. 2020;20:10.

17. Aungst TD, Patel R. Integrating digital health into the curriculum-considerations on the current landscape and future developments. J Med Educ Curric Dev. 2020;7:2382120519901275.

18. Elmansouri A, Murray $O$, Hall S, Border S. TEL methods used for the learning of clinical neuroanatomy. In: Rea PM, (ed). Biomedical Visualisation. Volume 8. Cham: Springer International Publishing; 2020. p. 43-73.

19. Mamtora S, Sandinha MT, Ajith A, Song A, Steel DHW. Smart phone ophthalmoscopy: a potential replacement for the direct ophthalmoscope. Eye. 2018;32:1766-71.

20. Shikino K, Suzuki S, Hirota $Y$, Kikukawa M, Ikusaka M. Effect of the iExaminer teaching method on fundus examination skills a randomized clinical trial. JAMA Netw Open. 2019;2:e1911891.

21. Schulz C, Moore J, Hassan D, Tamsett E, Smith CF. Addressing the 'forgotten art of fundoscopy': evaluation of a novel teaching ophthalmoscope. Eye (Lond). 2016;30:375-84.

22. Lee GA, Shah P. Use of a high-resolution camera (GoPro) for the slit lamp. Clin Exp Ophthalmol. 2018:46:447-9.
23. Jaffar AA. YouTube: an emerging tool in anatomy education. Anat Sci Educ 2012;5:158-64.

24. Root T. The easy way to learn ophthalmology. Timroot.com. 2021. Available at https://timroot.com/. [Accessed June 7, 2021].

25. Rajak S, Selva D, Davis G, Watanabe A, Handa Y. EyeSurgeryVideos.net. Oculoplastic EyeSurgeryVideos.net. 2015. Available at: https://oculoplastic.eyesurgeryvideos.net/ [Accessed May 29, 2021].

\section{ACKNOWLEDGEMENTS}

We would like to thank the continued efforts of all pedagogues involved in undergraduate ophthalmology education.

\section{AUTHOR CONTRIBUTIONS}

YSB finalised the paper. YSB, HN, NT, PG and SR all contributed equally to the ideation, writing and editing of this paper.

\section{COMPETING INTERESTS}

The authors declare no competing interests.

\section{ADDITIONAL INFORMATION}

Correspondence and requests for materials should be addressed to Y.S-B.

Reprints and permission information is available at http://www.nature.com/ reprints

Publisher's note Springer Nature remains neutral with regard to jurisdictional claims in published maps and institutional affiliations. 